\title{
Design and Development of Web-Based Information System for The Batik Industry
}

\author{
Indah Soesanti $^{1}$
}

\begin{abstract}
An Information system is any combination of information technology and people's activities using that technology to support operations, management, and decision-making. Some industries need web-based information system. Information system for the batik industry is designed to process data such as text, image, and produce information. The planning of webbased information systems needs a proactive review of the capabilities of the Internet technology to serve the particular needs of the firm and its customers. Process steps for designing the batik industry information system are software architecture, algorithm, data structure, and interface representations. The results show that the web-based information system that designed in this research is implemented successfully.
\end{abstract}

Keywords — Information system, web-based, data, batik industry, image, information technology.

\section{INTRODUCTION}

$\mathrm{T}$ he design of Information System can be taken as a problem which involves human sciences, resources, and Information Technology. Information system is a combination of information technology and human activities that use information technology to support the activities, operations, management and decision-making. Information and communication technology has become a very important requirement in many fields, especially for the purposes of analysis and decision-making to a problem.

Web-based technology is one of information and communication technology applications. The development of web technology is very fast both related devices as well as software-hardware devices associated with it (Mao et al, 2001, Antilla, et al, 2003, Caluya, et al., 2005). This development allows the required information can be accessed any where and at any time.

In the application of web technology, the industry use it, especially in information systems for any purposes. Many industries use the Internet media promotion, sales, communication with business relations, production monitoring, etc. (Iannaccone, 2001). In terms of the development of database information systems, webbased technology applications have been carried out by the industry, because of its complexity of the production process, database management, to marketing processes (Cockburn and McKenzie, 2001).

Application of web technology for information systems used in medium and small industries is very important, because the information systems can help improve productivity and competitiveness. Batik is one of the original indigenous industry that existed long ago in the land of Indonesia, which is rich in style and typical batik patterns (Soesanti, 2009, 2013), and have preserved its existence. Therefore it is obligatory for all parts of Indonesia, including from the college to maintain and preserve batik industry which is the ancestral heritage of Indonesia and is an excellent product that has the potential of high competitiveness in the international world.

${ }^{1}$ Indah Soesanti is with Departement of Electrical Engineering, Faculty of Engineering, Universitas Gadjah Mada, Yogyakarta, Indonesia. E-mail: indsanti@gmail.com.
This is supported by the fact that the body UNESCO world has recognized that batik is Indonesian capital of a nation.

\section{FUNDAMENTAL}

Previous studies of information system, as was done by Reimer (2004), Kellar (2008), Meyer, et al. (2009) and Freihat (2012) is mostly non-adaptive and do not use image compression techniques based intelligent systems. So in this study are novelty and innovation in batik image compression based on intelligent systems so as to minimize memory while maintaining information quality. While originality lies in its application in batik industry. While the study by Ballenger (2005) focuses on the management of the database in the medical field with data, mostly text data, and has not been applied to image data. Information system is a set of components forming a system that has the relationship between the components with other components aimed at producing the information in a particular field. In the classification system of information needed flow of information, this is due to the need for a diversity of information by the user information. Model of information system development can be done with the following methods:

1. Linear Sequential Model; need systematic and sequential approach to the steps of analysis, design, coding, testing and maintenance.

2. Model Prototype; method by presenting a complete picture of the system, the customer can see the side view of the system modeling and procedural techniques to be built.

3. Rapid Application Development (RAD); has a high speed of adaptation, can be made quickly with component-based development approach.

4. Model of Revolutionary or spiraling; revolutionary method is designed with clear phases, but is open to the participation of the buyer to participate determine system modeling.

5. 4GT Technique; constructed using non- procedural language for database query, report generation, data manipulation, definition and interaction on the monitor screen, and spreadsheet capabilities. 


\section{METHOD}

Design of web-based information systems web-based batik industry is described as follows. Information system design has been done in this study are:

\section{A. Analysis Phase}

At this stage identifying problems and finding solutions to overcome the problems. Steps taken begin with gathering information by coordinating with industry partners to understand the present and what the future needs. Information on the design and development of information systems is also derived from the literature and journals.

\section{B. Design Phase}

Information system design has focused on the various stages of the program are clear attributes, namely: software architecture, detailed procedure algorithm),a data structure and interface representations.

\section{Coding}

Coding phase is the phase that generates the design translated into the programming language of physical form or table form, function and procedures.

\section{Testing}

Testing phases were calculated using Blackbox Testing. Blackbox testing application compatibility testing has resulted with the system function ormfunctional ability.

\section{E. Maintenance}

Maintenance phase will continue when the information system has been successfully working properly. Here including improving maintenance and development of the system.

Relation scheme in the design of the database structure shown in Figure 2 (Nordbotten, 2008).

\section{RESULTS AND DISCUSSION}

Research results of Web-Based Information Systems applied to batik industry in Yogyakarta Indonesian for the login page and the data of production are shown in Figure 3 to 5 .

Information Systems for Customer Data is shown in Figure 6. All of information system pages have been successfully tested and are able to provide the required information.

\section{CONCLUSION}

Web-based information systems are designed on the batik industry in the wake of this study, in general, has managed to function as expected. Login page, the data of production, the data of customer, all have been successfully tested and are able to provide the required information.

\section{ACKNOWLEDGEMENT}

The authors gratefully acknowledge the contributions of the DIKTI, Ministry of Education and Culture, Republic of Indonesia, for funding this research.

\section{REFERENCES}

[1]. Antila, S., Kivikko, K., Trygg, P., Mäkinen A., and Järventausta, P., 2003, "Power Quality Monitoring of Distributed Generation Units Using a Web-based Application”, IEEE Papers.

[2]. Ballenger, R.M., 2005, “A Database Design and Development Case: Elk County Pediatric Medical Center”, Journal of Information Systems Education, Vol. 14(3).

[3]. Caluya, S.S., and Bautista, R., 2005, “A Proposed Web-Based Locator and Monitoring System for Tools and Equipment in Laboratory and Shop of TIP Arlegui”, Research Reflections and Innovations in Integrating ICT in Education.

[4]. Freihat, S., 2012, "The Role of Marketing Information System in Marketing Decision-making in JORDANIAN SHAREHOLDING Medicines Production Companies”, IJRRAS 11 (2) May 2012.

[5]. Iannaccone, G., Diot, C., Graham, I., and McKeown, N., 2001 "Monitoring very high speed links. In Proceedings of Internet Measurement Workshop 2001 (IMW’01), pages 267-271, San Francisco, November 2001.

[6]. Kellar, M., 2008, “An Overview of Web-Based Monitoring: Future Directions and Challenges”, IEEE Papers.

[7]. Mao, Y., Chen, K., Wang, D., and Zheng, W., 2001 "Clusterbased online monitoring system of web traffic. In Proceedings of the Third International Workshop on Web Information and Data Management, pages 47-53.

[8]. Meyer, C.H., M. Fritz, G. Schiefer, 2009, "The design of a marketing information system to enhance the competitiveness of agricultural commodities: some evidence from the grain sector”, EFITA Conference.

[9]. Nordbotten, J. C., 2008, "Multimedia Information Retrieval System”, DRAFT v2.0.

[10]. Reimers, K., 2004, “The Shaping of Inter-Organisational Information Systems: Main Design Considerations Of An International Comparative Research Project”, Proceedings of 17th Bled eCommerce Conference eGlobal, Bled, Slovenia, June 21 - 23, 2004.

[11]. Soesanti, I., 2009, Design of Batik Production Process Monitoring Based on Web Technology, Proceeding of National Seminar CITEE 2009, Electrical Ebngineering of UGM, Yogyakarta.

[12]. Soesanti, I., Widodo, T.S., 2013, Classification of Batik Pattern Based on Eigenimage Feature Extraction, Proceeding of National Seminar on Annual Engineering Seminar 2013, Engineering Faculty of UGM, Yogyakarta, Indonesia. 



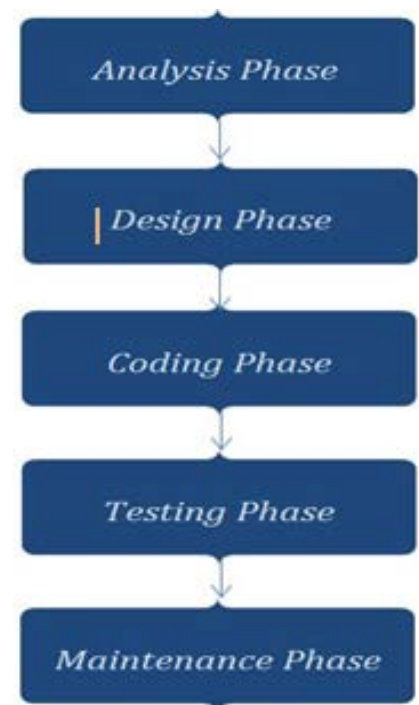

Figure 1. Design of web-based information system

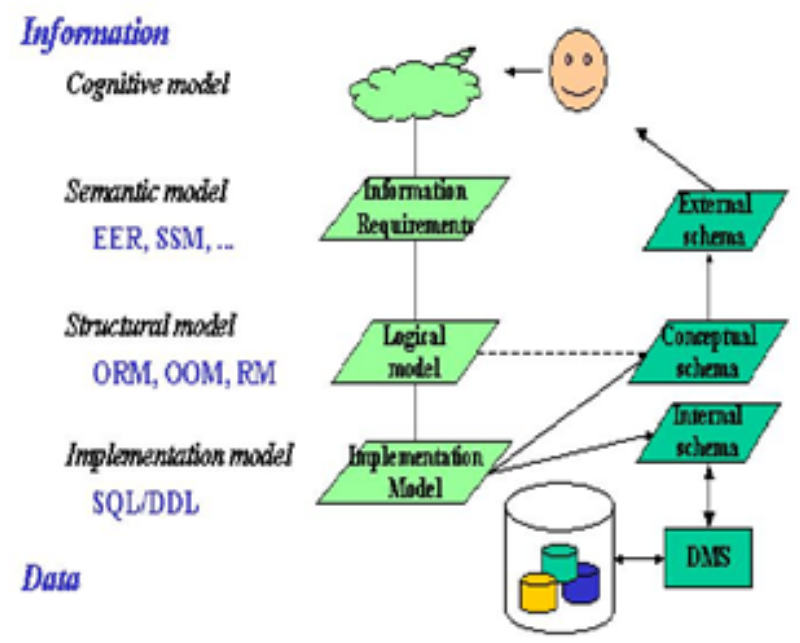

Figure 2. The scheme in data base structure design (Nordbotten, 2008)

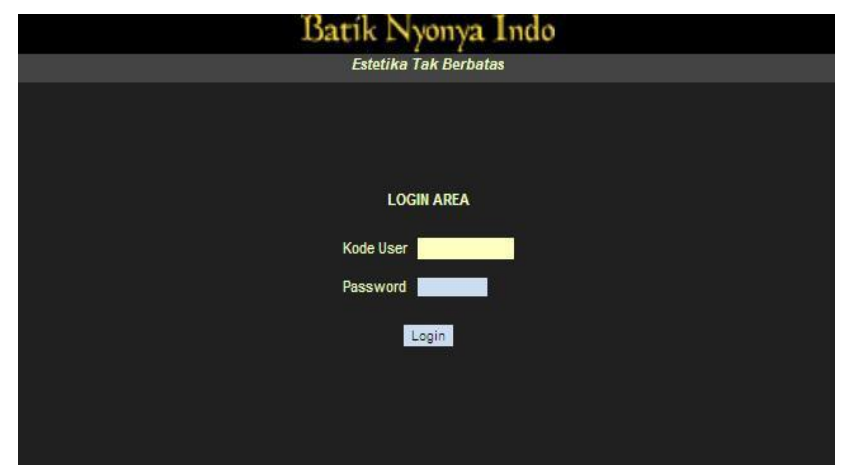

Figure 3. Login page

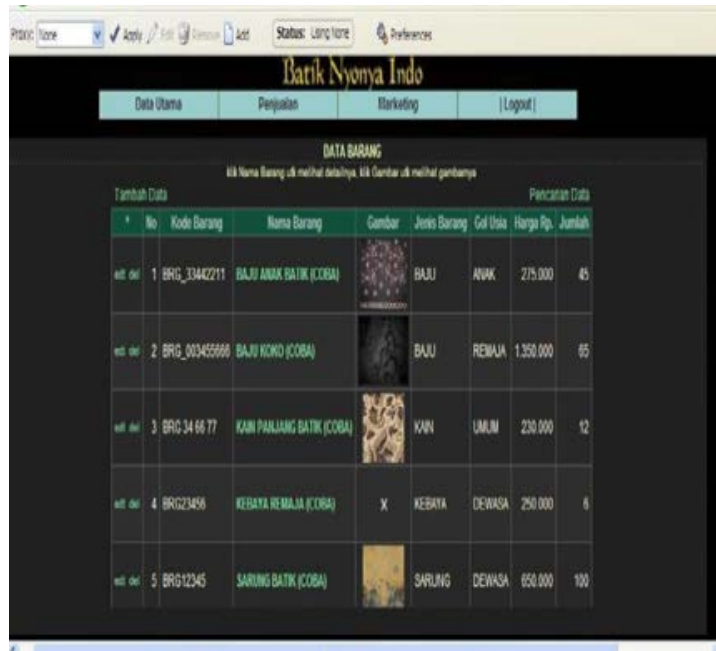

Figure 4. Production data page

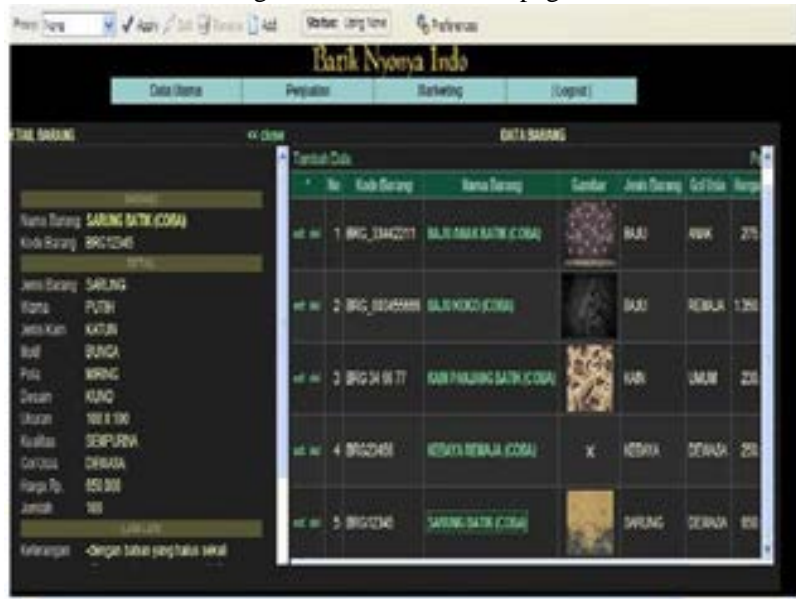

Figure 5. Detail of production data page

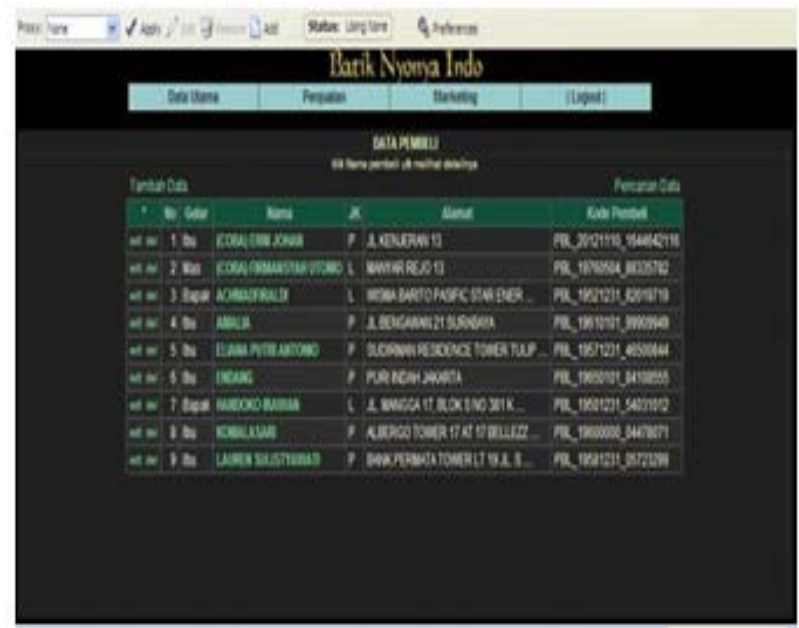

Figure 6. Customers data page 